\title{
The Hypocholesterolemic Effects of Eryngium carlinae F. Delaroche Are Mediated by the Involvement of the Intestinal Transporters ABCG5 and ABCG8
}

\author{
Ibrahim Guillermo Castro-Torres, ${ }^{1}$ Minarda De la O-Arciniega, ${ }^{2}$ \\ Elia Brosla Naranjo-Rodríguez, ${ }^{3}$ Víctor Alberto Castro-Torres, ${ }^{1}$ \\ Miguel Ángel Domínguez-Ortíz, ${ }^{4}$ and Mariano Martínez-Vázquez ${ }^{1}$ \\ ${ }^{1}$ Instituto de Química, Universidad Nacional Autónoma de México (UNAM), Ciudad de México, Mexico \\ ${ }^{2}$ Área Académica de Farmacia, Instituto de Ciencias de la Salud, Universidad Autónoma del Estado de Hidalgo, \\ Pachuca de Soto, HGO, Mexico \\ ${ }^{3}$ Departamento de Farmacia, Facultad de Química, UNAM, Ciudad de México, Mexico \\ ${ }^{4}$ Laboratorio de Productos Naturales, Instituto de Ciencias Básicas, Universidad Veracruzana, Xalapa de Enríquez, VER, Mexico
}

Correspondence should be addressed to Mariano Martínez-Vázquez; marvaz@unam.mx

Received 13 August 2017; Revised 24 October 2017; Accepted 22 November 2017; Published 14 December 2017

Academic Editor: Roberto K. N. Cuman

Copyright (c) 2017 Ibrahim Guillermo Castro-Torres et al. This is an open access article distributed under the Creative Commons Attribution License, which permits unrestricted use, distribution, and reproduction in any medium, provided the original work is properly cited.

\begin{abstract}
Hypercholesterolemia is a metabolic disorder characterized by a high concentration of cholesterol in the blood. Eryngium carlinae is a medicinal plant used to treat lipid diseases. The goal of this work was to evaluate, in a model of hypercholesterolemia in mice, the hypocholesterolemic effect of a hydroalcoholic extract of E. carlinae and its main metabolite, D-mannitol. Biochemical analyses of serum lipids and hepatic enzymes were performed by photocolorimetry. We performed histopathological studies of the liver and the expression of the intestinal cholesterol transporters Abcg5 and Abcg8 was determined by standard western blot method. Our results showed that hydroalcoholic extract at doses of $100 \mathrm{mg} / \mathrm{kg}$ and D-mannitol at doses of $10 \mathrm{mg} / \mathrm{kg}$ reduced the concentration of both total cholesterol and non-HDL cholesterol, without altering the concentration of HDL cholesterol and without damage to hepatocytes. Treatment with the extract increased Abcg8 intestinal transporter expression, while D-mannitol decreased the expression of the two Abcg5/Abcg8 transporters, compared with the hypercholesterolemic group. Considering that Abcg5/Abcg8 transporters perform cholesterol efflux, our results demonstrate that the lipid-lowering effect of the hydroalcoholic extract may be associated with the increase of Abcg8 expression, but the hypocholesterolemic effect of D-mannitol is independent of overexpression of these intestinal transporters and probably they have another mechanism of action.
\end{abstract}

\section{Introduction}

Hypercholesterolemia is a metabolic disorder characterized by an increase in the concentration of plasma cholesterol (above $200 \mathrm{mg} / \mathrm{dL}$ ); it is considered the primary risk factor for developing cardiovascular disease (atherosclerosis) [1, 2]. Hypercholesterolemia can be classified as primary if this is associated with congenital problems or improper food habits. When the hypercholesterolemia is associated with some disease such as diabetes mellitus, acute renal failure, or liver failure or the intake of types of drugs it is classified as secondary. Primary hypercholesterolemia is the most prevalent [3]. HMG-CoA reductase inhibitors ("statins") represent the most effective and widely prescribed drugs currently available for the reduction of low-density lipoprotein cholesterol. Although in general these drugs have proven their therapeutic value adverse events have been reported. Skeletal muscle-related events are the most common adverse events of statin treatment [4]. There has also been an increase in the number of reports of suspected psychiatric adverse reactions associated with statins [5]. Furthermore, statins may partially operate by lowering testosterone [5]. 
TABLE 1: Experimental groups.

\begin{tabular}{|c|c|c|}
\hline Number & Experimental group & Treatment \\
\hline (1) & Control & Standard diet (Laboratory Rodent Diet 5001) ad libitum \\
\hline (2) & Hypercholesterolemia & Hypercholesterolemic diet ( $1 \%$ cholesterol, $0.5 \%$ cholic acid) ad libitum \\
\hline (3) & Ezetimibe & $\begin{array}{l}\text { Ezetimibe } 10 \mathrm{mg} / \mathrm{kg} \text { and hypercholesterolemic diet ad libitum (Merck/Schering-Plough } \\
\text { Pharmaceuticals, USA) }\end{array}$ \\
\hline (4) & Hydroalcoholic extract & $\begin{array}{l}\text { Extract of Eryngium carlinae at a dose of } 100 \mathrm{mg} / \mathrm{kg} \text { and hypercholesterolemic diet and water ad } \\
\text { libitum }\end{array}$ \\
\hline (5) & Hydroalcoholic extract & Extract of Eryngium carlinae at a dose of $500 \mathrm{mg} / \mathrm{kg}$ and hypercholesterolemic diet ad libitum \\
\hline (6) & $\begin{array}{l}\text { Hexa-O-acetyl-D- } \\
\text { mannitol }\end{array}$ & Mannitol hexaacetate at a dose of $10 \mathrm{mg} / \mathrm{kg}$ and hypercholesterolemic diet ad libitum \\
\hline (7) & D-Mannitol & D-Mannitol at a dose of $10 \mathrm{mg} / \mathrm{kg}$ and hypercholesterolemic diet ad libitum \\
\hline
\end{tabular}

Different treatments during the evaluation of Eryngium carlinae. All treatments were administered every day at 15:00 $\mathrm{h}$ for four weeks.

Ezetimibe is another popular hypolipidemic agent. This drug inhibits the intestinal absorption of cholesterol from dietary and biliary sources by impeding the transport of cholesterol across the intestinal wall [6]. Ezetimibe does not affect the absorption of bile acids, fatty acids, fat-soluble vitamins, or triglycerides. However, it inhibits the expression of the Niemann-Pick C1L1 protein [7]. Nevertheless, there are reports concerning alleged psychiatric unfavorable reactions associated with ezetimibe [5].

Due to side effects of these drugs other therapeutic agents have been sought. Among them are the so-called medicinal plants. For example, the Malaysian medicinal plant Hibiscus rosa-sinensis reduces blood pressure and cholesterol concentration in blood. This is due to the existence of saponins in this species [8]. Saponins bind to cholesterol to form insoluble complexes excreted via the bile. This prevents cholesterol reabsorption and results in a reduction of serum cholesterol [9]. Camellia japonica and Amaranthus viridis have also demonstrated important lipid-lowering effects in experimental models $[10,11]$.

In the Mexican traditional medicine, there are two species, Eryngium heterophyllum and E. carlinae Delaroche which both under the trivial name of "toad herb" have a great ethnopharmacological tradition to relieve some gastrointestinal diseases and to treat hypercholesterolemia [12]. An exhaustive search of the literature indicates a single report linking $E$. carlinae with hypolipidemic activity. This report demonstrates that an ethanolic extract of this species reduced the levels of creatinine, uric acid, total cholesterol, and triglycerides, parameters that are exacerbated in diabetes, in streptozotocin-induced diabetic rats. However, no toxicity data or phytochemical analyses were reported. Neither of the rats fed hypercholesterolemic diets was treated with the extract [13]. On the other hand, it is known that Abcg5 and Abcg8 proteins are responsible for mediating cholesterol efflux [14]. Therefore, inhibition of these proteins could trigger a hypercholesterolemia process [14].

Considering the above, we decide to evaluate the effectiveness of a hydroalcoholic extract of Eryngium carlinae (ECHE) and its major metabolite, D-mannitol, as hypocholesterolemic agents in hypercholesterolemic mice. We also studied the possible involvement of the intestinal proteins Abcg5 and Abcg8 in the mechanism of action of these drugs.

\section{Material and Methods}

2.1. Animal Experimental Protocol. Male CD1 mice $(30 \pm 2 \mathrm{~g}$, 8-10 weeks old) were used (Harlan Laboratories, Mexico). Animals were housed in plastic cages in a temperaturecontrolled room with $12: 12 \mathrm{~h}$ light-dark cycles and provided ad libitum with access to food and water. After one week of acclimatization, the animals were randomly divided into 7 experimental treatments groups $(n=6)$ (Table 1). For eight weeks, group 1 (control group) was maintained on a regular chow diet (Laboratory Rodent Chow 5001, Harlan Laboratories, Mexico).

The other six groups were feeding with a diet enriched with $1 \%$ cholesterol and $0.5 \%$ cholic acid (hypercholesterolemic/lithogenic diet, Harlan Laboratories TD 03451, 1\% cholesterol, $0.5 \%$ sodium cholate). The mice had free access to this diet for four weeks. After this period, we found that the mice were already hypercholesterolemic, compared with healthy mice. At this point, the different treatments were administered orally, every day at 15:00 h, for the rest of the four weeks along with the hypercholesterolemic diet. Animal care and procedures were conducted according to the guidelines approved by Norma Oficial Mexicana (NOM062-ZOO-1999) and were subjected to experimental protocols approved by the Comité Interno Ético para el Uso y Cuidado de los Animales de Laboratorio (15-CIECUAL, February 2017), Instituto de Ciencias de la Salud, Universidad Autónoma del Estado de Hidalgo.

2.2. Chronic Toxicity Test. The chronic toxicity test was performed using female CD1 mice $(30 \pm 2 \mathrm{~g}$ in weight and approximate age of $8-10$ weeks), which were given orally the alcoholic extract (ECHE), D-mannitol, or hexa-O-acetyl$\mathrm{D}$-mannitol under the same schedule as the hypercholesterolemia study.

2.3. Biochemical Analysis. After eight weeks, the animals of all groups were fasted, weighed, and anesthetized (sodium 
pentobarbital $70 \mathrm{mg} / \mathrm{kg}$ ). The blood samples were drawn from the retroorbital vein; then the mice were sacrificed under anesthesia. Serum was obtained from blood samples by centrifugation, and the different biochemical parameters were measured. Biochemical analysis was carried into a Randox Daytona automate using a commercial kit (total cholesterol CH201, $6 \times 100 \mathrm{~mL}$; HDL cholesterol-direct clearance method, $\mathrm{CH} 1383, R 13 \times 2.5 \mathrm{~L} R 21 \times 2.5 \mathrm{~L}$; LDL cholesterol CH2656 R1 $6 \times 78 \mathrm{~mL} \mathrm{R2} 3 \times 52 \mathrm{~mL}$ and glucose, GOD-PAP, and hexokinase, GL $36410 \times 100 \mathrm{~mL}$ ) according to the manufacturer's protocol.

We reported total cholesterol, HDL, and non-HDL cholesterol concentrations (Enzymatic Methods, Accelab, Mexico). In chronic toxicity test, we quantified the concentration of aspartate transaminase (AST) and alanine transaminase (ALT) liver enzymes, as well as the total cholesterol concentration (Accelab, Mexico).

2.4. Histopathological Study. Livers were entirely randomly selected and fixed in $4 \%$ neutral buffered formaldehyde embedded in paraffin, and $5 \mu \mathrm{m}$ thin slices were cut and stained with hematoxylin-eosin. A pathologist performed the histological studies.

2.5. Molecular Analysis. The first 5 centimeters of the small intestine corresponding to the jejunum were used. We analyze this inner region because it is the site where cholesterol is absorbed. The intestinal tissue was homogenized by mixing it with a protease inhibitor, and the cells were subsequently lysed and centrifuged. The quantified protein concentration was performed by the Lowry method.

The expression of major intestinal cholesterol transporters in mice, Abcg5 and Abcg8, was analyzed by the standard western blot method. We perform 4 replicates of these molecular analyses. Antibodies were purchased from Santa Cruz Biotechnology, Inc., México: ABCG5 (H-300): sc-25796, rabbit polyclonal; ABCG8 (H-300): sc-30111, rabbit polyclonal and b-actin (C4); HRP: sc-47778, mouse monoclonal. We used $12 \%$ SDS-polyacrylamide gel and proteins were transferred to PVDF membranes. Membranes were incubated in blocking buffer. Primary antibodies were diluted as 1:100 in blocking buffer and incubated overnight at $4^{\circ} \mathrm{C}$. Secondary antibody was diluted as 1:2000 and coupled with horseradish peroxidase. Proteins were visualized by chemiluminescence and our results were normalized with $\beta$ actin.

2.6. General Experimental Procedures. NMR spectra were acquired in $\mathrm{CDCl}_{3}$ at room temperature on a Bruker-Fourier $(\mathrm{A} 300 \mathrm{MHz})$ spectrometer and the chemical shifts are given as $\delta$ values with reference to tetramethylsilane (TMS) as the internal standard.

2.7. Plant Material. Aerial parts of E. carlinae Delaroche (Apiaceae) were collected near Atlixco, Puebla, Mexico, in July 2011. The plant was dried, ground, and stored in the refrigerator at $0^{\circ} \mathrm{C}$ until it was used. The species was taxonomically identified by Dr. Isolda Luna and a voucher
(097586) has been deposited at Herbario de la Facultad de Ciencias, México (FCME).

2.8. Extraction and Isolation. The air-dried and ground aerial parts of E. carlinae (1000 g) were extracted with a mixture of $\mathrm{EtOH}-\mathrm{H}_{2} \mathrm{O}(7: 3)(4 \mathrm{~L})$ at $60^{\circ} \mathrm{C}$ under constant shaking for $2 \mathrm{~h}$. The solvent was filtered and evaporated under reduced pressure to give $10.55 \mathrm{~g}$ of hydroalcoholic extract (ECHE).

2.9. D-Mannitol. Treatment of ECHE (4g) with $\mathrm{MeOH}$ $(50 \mathrm{~mL})$ afforded a solid and a solution. The solution was filtered and mixed with activated carbon and subsequently gently heated. The solution was filtered using a Büchner funnel with celite pad, and it was evaporated under reduced pressure to give a solid which was purified by crystallization method with $\mathrm{MeOH}$ to give $650 \mathrm{mg}$ of $\mathrm{D}$-mannitol. The identity of this metabolite was achieved by comparison of its spectroscopic and spectrometric data with those reported in the literature [15].

2.10. Hexa-O-acetyl-D-mannitol. The residue insoluble in $\mathrm{MeOH}(510 \mathrm{mg})$ was dissolved in dry pyridine $(3 \mathrm{~mL})$ and $\mathrm{Ac}_{2} \mathrm{O}(3 \mathrm{~mL})$ was added. The reaction mixture was heated at $60^{\circ} \mathrm{C}$ during $4 \mathrm{~h}$. Usual work-up provided a residue which was chromatographed on a silica gel open column using $n$ hexane-EtOAc solvent mixture of increasing polarity. Hexa$\mathrm{O}$-acetyl-D-mannitol was isolated from the fractions eluted with $9: 1$, hexane: EtOAc. The identity of the acetate derivate was achieved by comparison of its spectroscopic and spectrometric data with those reported in the literature [16].

2.11. Statistical Analysis. The statistical analyses were performed using a Sigma Plot program. Data were analyzed using one-way analysis of variance (one-way ANOVA) and Tukey's post hoc test. Each point in the tables and figures represents the mean \pm standard error.

\section{Results}

3.1. Phytochemistry. Treatment of ECHE with methanol yielded both a methanol solution and a methanol-insoluble solid; the latter phase was the most abundant. D-Mannitol was isolated from the methanol soluble fraction by evaporation of the solvent under reduced pressure and treatment of the residue with methanol. The methanol-insoluble solid $(510 \mathrm{mg})$ was dissolved in pyridine and treated with acetic anhydride to yield $670 \mathrm{mg}$ of acetylation product. The chromatographic separation of this product yielded $135 \mathrm{mg}$ of hexa-O-acetyl-D-mannitol. The identification of the D-mannitol and its acetylated derivative was achieved by comparison of its spectral and physical data with those in literature $[15,16]$.

3.2. Chronic Toxicity. The mice showed no evident signs of toxicity (motor incoordination, piloerection, dilation of pupils, etc.) after being given both 100 and $500 \mathrm{mg} / \mathrm{kg}$ doses of the extract for 4 weeks. However, the hydroalcoholic extract caused liver toxicity in mice at doses of $500 \mathrm{mg} / \mathrm{kg}$, 
TABLE 2: Analysis of biochemical parameters in toxicity test.

\begin{tabular}{|c|c|c|c|c|}
\hline Number & Experimental group & Total cholesterol (mg/dL) & $\operatorname{ALT}(\mathrm{IU} / \mathrm{L})$ & AST (IU/L) \\
\hline (1) & Control & $125.1 \pm 2.1$ & $84.3 \pm 1.3$ & $42.2 \pm 0.5$ \\
\hline (2) & ECHE $(100 \mathrm{mg} / \mathrm{kg})$ & $129.6 \pm 1.2$ & $92.6 \pm 0.6$ & $46.3 \pm 0.8$ \\
\hline (3) & ECHE $(500 \mathrm{mg} / \mathrm{kg})$ & $120.2 \pm 3.3$ & $159.5 \pm 4.8^{*}$ & $182.2 \pm 2.6^{*}$ \\
\hline (4) & Hexa-O-acetyl-D-mannitol $(10 \mathrm{mg} / \mathrm{kg})$ & $130.1 \pm 3.3$ & $84.7 \pm 0.5$ & $53.3 \pm 0.8$ \\
\hline (5) & D-Mannitol (10 mg/kg) & $127.1 \pm 3.7$ & $91.9 \pm 0.8$ & $58.5 \pm 0.4$ \\
\hline
\end{tabular}

${ }^{*}$ Values indicate significant statistical difference $(p<0.05)$ between groups treated with extracts and metabolites versus control group. One-way ANOVA with Tukey's post hoc test. Values are reported as mean \pm standard error using six mice in each experimental group.

TABLE 3: Analysis of serum cholesterol.

\begin{tabular}{|c|c|c|c|c|}
\hline \multirow{2}{*}{ Number } & \multirow{2}{*}{ Experimental group } & \multicolumn{3}{|c|}{ Cholesterol concentration (mg/dL) } \\
\hline & & Total & HDL & Non-HDL \\
\hline (1) & Control & $148.3 \pm 4.4$ & $126.5 \pm 4.8$ & $21.8 \pm 0.7^{*}$ \\
\hline (2) & Hypercholesterolemia & $223.5 \pm 2.6$ & $97.5 \pm 5.6$ & $132.8 \pm 4.8$ \\
\hline (3) & Ezetimibe (10 mg/kg) & $128.1 \pm 1.8^{*}$ & $119.8 \pm 2.8^{*}$ & $10.5 \pm 0.7^{*}$ \\
\hline (4) & ECHE (100 mg/kg) & $139.7 \pm 2.8^{*}$ & $120.9 \pm 3.7^{*}$ & $17.1 \pm 0.6^{*}$ \\
\hline (5) & ECHE $(500 \mathrm{mg} / \mathrm{kg})$ & $129.6 \pm 2.9^{*}$ & $112.5 \pm 3.1$ & $17.2 \pm 0.9^{*}$ \\
\hline (6) & Hexa-O-acetyl-D-mannitol (10 mg/kg) & $198.1 \pm 4.9$ & $98.1 \pm 3.2$ & $93.7 \pm 2.2^{*}$ \\
\hline (7) & D-Mannitol $(10 \mathrm{mg} / \mathrm{kg})$ & $137.6 \pm 3.3^{*}$ & $117.9 \pm 2.7^{*}$ & $19.1 \pm 1.5^{*}$ \\
\hline
\end{tabular}

${ }^{*}$ Values indicate significant statistical difference $(p<0.05)$ between groups with different treatments versus group treated with hypercholesterolemic diet. One-way ANOVA with Tukey's post hoc test. Values are reported as mean \pm standard error using six mice in each experimental group.

as evidenced by an increase in the concentration of aspartate transaminase (AST) and alanine transaminase (ALT) compared to the control group (Table 2). On the other hand, D-mannitol and its derivative caused a slight increase in the concentration of liver enzymes; however, these effects were less toxic than that exerted by the extract at $500 \mathrm{mg} / \mathrm{kg}$ (Table 2). Additionally, the extract and the D-mannitol as well as its acetyl derivative did not alter the concentration of cholesterol; the values obtained in the different treatments can be compared with values obtained with normocholesterolemic mice (Table 2).

3.3. Cholesterol Concentration. For eight weeks mice had free access to cholesterol-rich diet. However, by the fourth week, according to our analysis, the animals were already hypercholesterolemic. Considering the above, we decided to start the administration of the different treatments along with the cholesterol-rich diet to the hypercholesterolemic mice at the fourth week and finish it until the eighth week. The mice that received the high cholesterol diet showed an increase in both total cholesterol levels and the non-HDL fraction, as well as a significant decrease in HDL cholesterol compared with control mice (Table 3 ). The mice treated with ezetimibe $(10 \mathrm{mg} / \mathrm{kg})$, ECHE (100 and $500 \mathrm{mg} / \mathrm{kg})$, and D-mannitol $(10 \mathrm{mg} / \mathrm{kg})$ significantly showed a reduction in the concentration of both total cholesterol and non-HDL cholesterol compared to the group that developed hypercholesterolemia. The latter revealed a total cholesterol concentration over $200 \mathrm{mg} / \mathrm{dL}$. On the other hand, treatments with ezetimibe, Dmannitol, and ECHE at $100 \mathrm{mg} / \mathrm{kg}$ doses caused an increase in HDL cholesterol levels compared to the hypercholesterolemic group. Although the hexa-O-acetyl-D-mannitol derivate also decreased the total cholesterol this reduction is not as pronounced as the nonacetylated compound. According to our results, the acetylated derivative preferably decreases the non-HDL concentration not that of HDL (Table 3).

3.4. Histopathology. Histopathology results were compared between different experimental groups (Figure 1). Our results showed that the liver tissues of normal diet mice group presented a moderate congestion in hepatocytes (10x magnification) (Figure 1(a)). Conversely, the liver tissues of the hypercholesterolemic group showed diffuse moderate hepatocellular degeneration, periportal inflammation in blood vessels, and damage to endothelium of sinusoids caused by a homogenous acellular material like fibrin (40x magnification) (Figure 1(b)). The liver samples of the ezetimibe group showed moderate chronic diffuse liver congestion with periportal fibrosis and there was moderate intrahepatic cholestasis (40x magnification) (Figure 1(c)). Almost the same results as the normal group were observed with the group treated at $100 \mathrm{mg} / \mathrm{kg}$ doses of extract (10x magnification) (Figure 1(d)). Although the treatment with extract at $500 \mathrm{mg} / \mathrm{kg}$ doses induced serum cholesterol levels, it produced damage in the liver. The liver samples of the latter group showed hepatocellular necrosis, moderate intrahepatic cholestasis, and hepatocellular degeneration (40x magnification) (Figure 1(e)). There were no apparent histological changes in groups treated with hexa-O-acetyl-D-mannitol (40x magnification) (Figure 1(f)) or D-mannitol (40x magnification) (Figure $1(\mathrm{~g})$ ).

3.5. Molecular Analysis. Since ECHE (100 mg/kg) showed a similar hypocholesterolemic activity compared to ECHE 

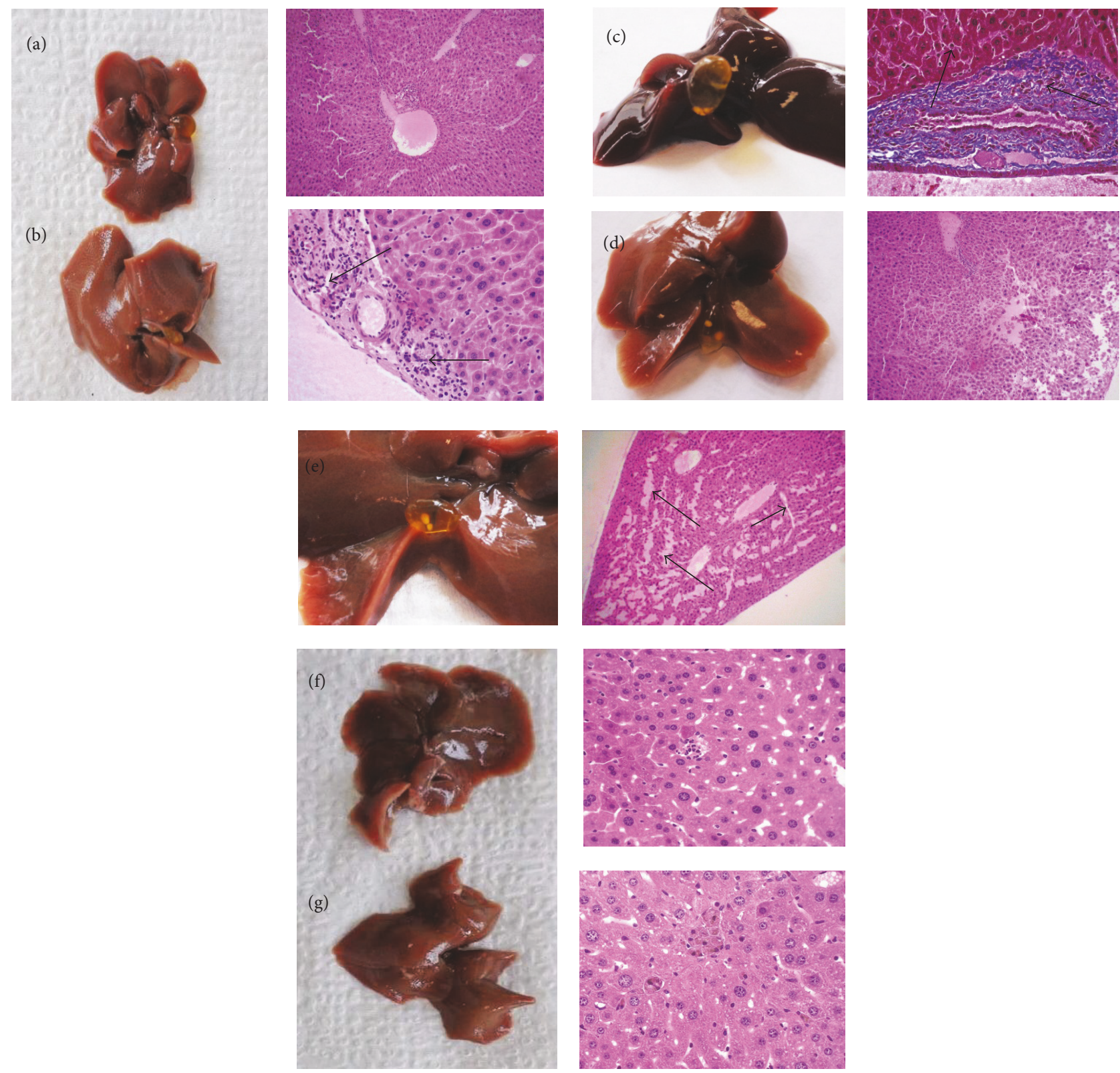

Figure 1: Histopathological microscopic examination in mice liver tissues. Control (a). Hypercholesterolemia (b). Ezetimibe $10 \mathrm{mg} / \mathrm{kg}$ (c). ECHE, $100 \mathrm{mg} / \mathrm{kg}$ (d). ECHE, $500 \mathrm{mg} / \mathrm{kg}$ (e). Hexa-O-acetyl-D-mannitol $10 \mathrm{mg} / \mathrm{kg}$ (f). D-Mannitol, $10 \mathrm{mg} / \mathrm{kg}$ (g). There were no apparent histological changes in control group fed with a regular chow diet (Figure 1(a)). In Figure 1(b), black arrows indicate the epithelial hyperplasia and granulocyte infiltration in liver of CD1 mice after being fed with a hypercholesterolemic diet. In Figure 1(c) the liver treated with ezetimibe also presented inflammatory infiltration and epithelial hyperplasia; black arrows indicate hepatocellular necrosis. In Figure 1(d) there were no apparent changes after treatment with ECHE $100 \mathrm{mg} / \mathrm{kg}$. In Figure 1(e) all liver tissues showed fibrosis bands (black arrows) and epithelial hyperplasia. There were no apparent histological changes in groups treated with hexa-O-acetyl-D-mannitol (Figure 1(f)) or D-mannitol (Figure $1(\mathrm{~g})$ ).

$(500 \mathrm{mg} / \mathrm{kg})$ without the induction of hepatotoxicity, only ECHE $(100 \mathrm{mg} / \mathrm{kg})$ was analyzed by western blot technique. Expression of Abcg8 intestinal transporter increased after treatments with hydroalcoholic extract at $100 \mathrm{mg} / \mathrm{kg}$ dose and with ezetimibe at doses of $10 \mathrm{mg} / \mathrm{kg}$ (Figure 2). These two treatments (ezetimibe and extract) appeared to increase the expression of Abcg5 and Abcg8 in the small intestine. On the other hand, the administration of D-mannitol and its hexa-acetyl derivative decreased the expression of Abcg5/ Abcg8 proteins, compared with hypercholesterolemic group.

\section{Discussion}

It has been proposed that two ATP-binding cassette (ABC) transporters, Abcg5 and Abcg8, restricted sterol absorption and promoted biliary sterol excretion in humans. Furthermore, it has been reported that increased expression of 

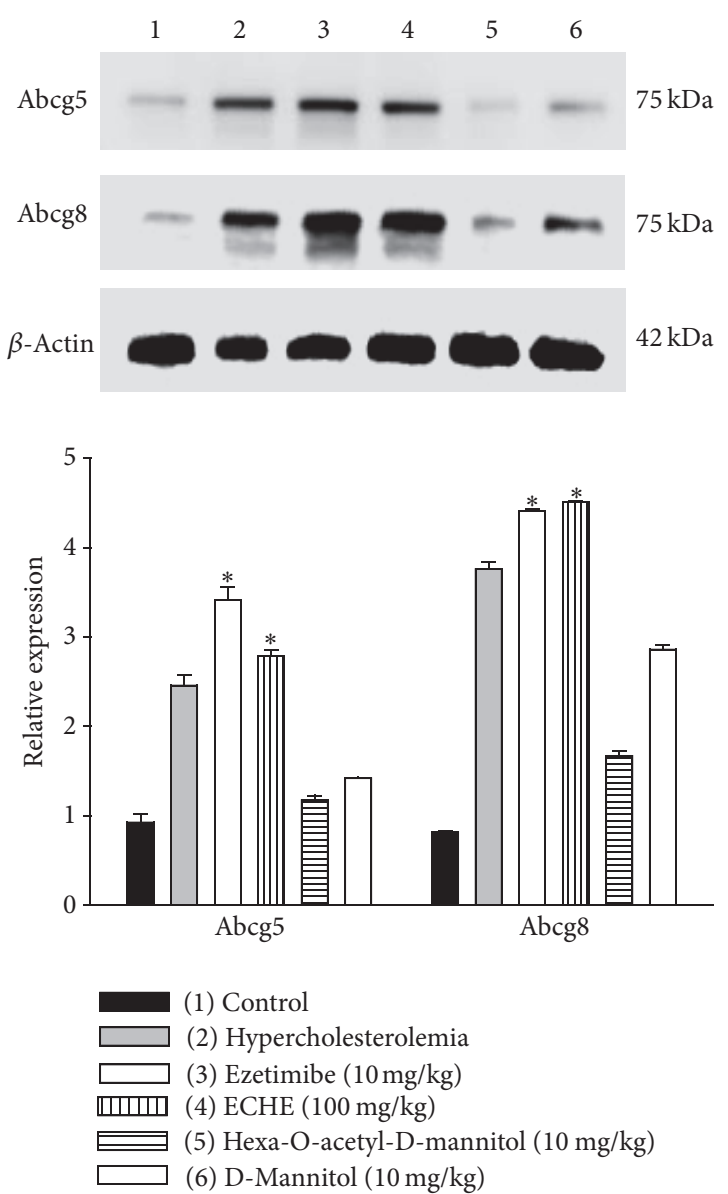

Figure 2: Western blot results. Western blot analysis of Abcg5 and Abcg88 in small intestine tissues of mice. Control (1), hypercholesterolemia (2), ezetimibe $10 \mathrm{mg} / \mathrm{kg}$ (3), ECHE $100 \mathrm{mg} / \mathrm{kg}$ (4), hexa-O-acetyl-D-mannitol (5), and D-mannitol (6). Total protein lysates were separated by $12-15 \%$ SDS-PAGE followed by western blot analysis using the indicated antibodies. $\beta$-Actin was used as a loading control for total cell extracts. Densitometry of western blots for ABCG5 and ABCG8, ${ }^{*} p<0.05$ comparing groups treated with ezetimibe $(10 \mathrm{mg} / \mathrm{kg})$ and ECHE $(100 \mathrm{mg} / \mathrm{kg})$ with hypercholesterolemic group.

ABCG5 and ABCG8 genes selectively drives biliary neutral sterol secretion and reduces intestinal cholesterol absorption $[17,18]$.

Taking the above into account, we studied the possible participation of these proteins in the antihyperlipidemic activity of ECHE, D-mannitol, and its hexa-acetate derivative in hypercholesterolemic mice.

The effect of dietary cholesterol on the expression of Abcg5 and Abcg8 in the small intestine is controversial [19]. Some studies in mice have shown that dietary supplementation of cholesterol increases the expression of Abcg5 and Abcg8 in the small intestine while other authors claimed that fat diet did not show any effect on the expression of these transporters $[17,20]$. Nevertheless, in our case, an overexpression of ABCG5/ABCG8 proteins was observed in the hypercholesterolemic group compared with the control group (Figure 2). Our results showed that ECHE at $100 \mathrm{mg} / \mathrm{kg}$ doses and ezetimibe at $10 \mathrm{mg} / \mathrm{kg}$ doses caused an increase in the expressions of the ABCG8 and ABCG5 transporters (Figure 2). It has been reported that the ABCG5/ABCG8 expression in both the liver and intestine protects animals from sterol accumulation, and intestinal ABCG5/ABCG8 contributes to extrahepatic cholesterol efflux in mice [18]. Jia and coworkers demonstrated, in knockout mice, that ABCG5/ABCG8 deficiency reduces the uptake and secretion of both dietary triglycerides and cholesterol by the intestine [21]. Therefore, our results suggested that ABCG8 could be involved in the hypolipidemic activities of ECHE.

However, D-mannitol and the hexa-O-acetyl-D-mannitol not only hindered overexpression of ABCG5/ABCG8 but also inhibited the overexpression of these proteins induced by the hypercholesterolemic diet (Figure 2). These results suggest that the antihypercholesterolemic properties of $\mathrm{D}$ mannitol seem to be independent of ABCG5/ABCG8 overexpression.

Under physiological conditions, dietary cholesterol is efficiently solubilized by bile salt-phospholipid mixtures in the form of either mixed micelles or vesicles that formed in bile [22]. Bile flow is generated by transepithelial transport of water and ionic/nonionic solutes via transcellular and paracellular pathways mainly driven by osmotic pressure [23]. D-Mannitol is the most widely used osmotic diuretic and can be absorbed solely by the paracellular route [24]; therefore, in our experimental study, this molecule could favor the osmotic pressure for proper regulation of bile composition. By having mixed micelles in the bile, it is possible to favor the adequate transport of cholesterol, preventing it from accumulating in the enterocytes and avoiding the development of hypercholesterolemia.

The latter result is a little surprising if we consider that the ECHE induced overexpression of the enzymes ABCG5/ ABCG8. However, there are several reports about the isolates from plants that lowered plasma cholesterol by increasing fecal excretion of acidic and neutral sterols in mice fed a cholesterol-enriched diet accompanied with downregulation of gene expression of intestinal ABCG8 [23-26].

\section{Conclusion}

In conclusion, we showed that ECHE $(100 \mathrm{mg} / \mathrm{kg})$ and Dmannitol $(10 \mathrm{mg} / \mathrm{kg})$ exert, each, hypolipidemic effects in hypercholesterolemic mice, with similar activity compared to ezetimibe $(10 \mathrm{mg} / \mathrm{kg})$, without causing damage to liver and without affecting the levels of HDL cholesterol. The hypocholesterolemic effect of ECHE seems to be mediated by ABCG5/ABCG8 intestinal transporters.

\section{Conflicts of Interest}

The authors declare no conflicts of interest.

\section{Acknowledgments}

Ibrahim Guillermo Castro-Torres is a doctoral student from Programa de Doctorado en Ciencias Biomédicas, Universidad Nacional Autónoma de México (UNAM), and received 
fellowship 278442 from CONACYT (CVU: 488911, no. Becario 278442). The authors thank M. en C. Antonio Nieto Camacho and M. en C. María Teresa Obdulia Ramírez Apan, Unidad de Pruebas Biológicas, Instituto de Química, Universidad Nacional Autónoma de México. The authors also thank Miss Graciela Ruiz of the Basic Research Unit of the National Institute of Cancerology for her technical help.

\section{References}

[1] S. D. De Ferranti, A. M. Rodday, M. M. Mendelson, J. B. Wong, L. K. Leslie, and R. C. Sheldrick, "Prevalence of familial hypercholesterolemia in the 1999 to 2012 United States national health and nutrition examination surveys (NHANES)," Circulation, vol. 133, no. 11, pp. 1067-1072, 2016.

[2] Z. Zhuang, C. Shan, B. Li et al., "Linarin Enriched Extract Attenuates Liver Injury and Inflammation Induced by High-Fat High-Cholesterol Diet in Rats," Evidence-Based Complementary and Alternative Medicine, vol. 2017, pp. 1-9, 2017.

[3] V. E. Bouhairie and A. C. Goldberg, "Familial Hypercholesterolemia," Endocrinology and Metabolism Clinics of North America, vol. 45, no. 1, pp. 1-16, 2016.

[4] Y. S. Chatzizisis, K. C. Koskinas, G. Misirli, C. Vaklavas, A. Hatzitolios, and G. D. Giannoglou, "Risk factors and drug interactions predisposing to statin-induced myopathy: Implications for risk assessment, prevention and treatment," Drug Safety, vol. 33, no. 3, pp. 171-187, 2010.

[5] C. M. Schooling, S. L. Au Yeung, G. Freeman, and B. J. Cowling, "The effect of statins on testosterone in men and women, a systematic review and meta-analysis of randomized controlled trials," BMC Medicine, vol. 11, no. 1, article no. 57, 2013.

[6] C. Gagné, H. E. Bays, S. R. Weiss et al., "Efficacy and safety of ezetimibe added to ongoing statin therapy for treatment of patients with primary hypercholesterolemia," American Journal of Cardiology, vol. 90, no. 10, pp. 1084-1091, 2002.

[7] A. A. Kei, T. D. Filippatos, and M. S. Elisaf, "The safety of ezetimibe and simvastatin combination for the treatment of hypercholesterolemia," Expert Opinion on Drug Safety, vol. 15, no. 4, pp. 559-569, 2016.

[8] D. Krishnaiah, T. Devi, A. Bono, and R. Sarbatly, "Studies on phytochemical constituents of six Malaysian medicinal plants," Journal of Medicinal Plants Research, vol. 3, no. 2, pp. 67-72, 2009.

[9] M. R. Malinow, P. McLaughlin, and G. O. A. L. Kohler andLivingston, "Alfalfa saponins: a family of substances potentially useful for the treatment of hypercholesterolemia," Clinical Research, vol. 25, no. 2, p. 97, 1977.

[10] H.-H. Lee, K. R. Paudel, J. Jeong et al., "Antiatherogenic effect of Camellia japonica fruit extract in high fat diet-fed rats ," Evidence-Based Complementary and Alternative Medicine, vol. 2016, Article ID 9679867, 8 pages, 2016.

[11] S. Salvamani, B. Gunasekaran, M. Y. Shukor, N. A. Shaharuddin, M. K. Sabullah, and S. A. Ahmad, "Anti-HMGCoA reductase, antioxidant, and anti-inflammatory activities of amaranthus viridis leaf extract as a potential treatment for hypercholesterolemia," Evidence-Based Complementary and Alternative Medicine, vol. 2016, Article ID 8090841, 2016.

[12] A. Navarrete, D. Niño, B. Reyes, C. Sixtos, E. Aguirre, and E. Estrada, "On the hypocholesteremic effect of Eryngium heterophyllum," Fitoterapia, vol. 61, no. 2, pp. 182-184, 1990.
[13] R. Noriega-Cisneros, O. Ortiz-Vila, E. Esquivel-Gutiérrez et al., "Hypolipidemic activity of eryngium carlinae on streptozotocininduced diabetic rats," Biochemistry Research International, Article ID 603501, 2012.

[14] I. G. Castro-Torres, R. D. J. Cárdenas-Vázquez, C. VelázquezGonzález et al., "Future therapeutic targets for the treatment and prevention of cholesterol gallstones," European Journal of Pharmacology, vol. 765, pp. 366-374, 2015.

[15] Q. Cui, I. A. Lewis, A. D. Hegeman et al., "Metabolite identification via the Madison Metabolomics Consortium Database," Nature Biotechnology, vol. 26, no. 2, pp. 162-164, 2008.

[16] J. Kuszmann, G. Medgyes, and S. Boros, "Synthesis of poly-Osulfated glycosides of 2,5-anhydro-D-mannitol," Carbohydrate Research, vol. 340, no. 10, pp. 1739-1749, 2005.

[17] L. Yu, J. Li-Hawkins, R. E. Hammer et al., "Overexpression of ABCG5 and ABCG8 promotes biliary cholesterol secretion and reduces fractional absorption of dietary cholesterol," The Journal of Clinical Investigation, vol. 110, no. 5, pp. 671-680, 2002.

[18] J. J. Repa, K. E. Berge, C. Pomajzl, J. A. Richardson, H. Hobbs, and D. J. Mangelsdorf, "Regulation of ATP-binding cassette sterol transporters ABCG5 and ABCG8 by the liver X receptors $\alpha$ and $\beta$," The Journal of Biological Chemistry, vol. 277, no. 21, pp. 18793-18800, 2002.

[19] J. Wang, M. A. Mitsche, D. Lütjohann, J. C. Cohen, X.-S. Xie, and H. H. Hobbs, "Relative roles of ABCG5/ABCG8 in liver and intestine," Journal of Lipid Research, vol. 56, no. 2, pp. 319-330, 2015.

[20] X.-H. Yu, K. Qian, N. Jiang, X.-L. Zheng, F. S. Cayabyab, and C.-K. Tang, "ABCG5/ABCG8 in cholesterol excretion and atherosclerosis," Clinica Chimica Acta, vol. 428, pp. 82-88, 2014.

[21] X. Jia, N. Ebine, I. Demonty et al., "Hypocholesterolaemic effects of plant sterol analogues are independent of ABCG5 and ABCG8 transporter expressions in hamsters," British Journal of Nutrition, vol. 98, no. 3, pp. 550-555, 2007.

[22] L. S. Zhang, M. Xu, Q. Yang, D. Lou, P. N. Howles, and P. Tso, "ABCG5/G8 deficiency in mice reduces dietary triacylglycerol and cholesterol transport into the lymph," Lipids, vol. 50, no. 4, pp. 371-379, 2015.

[23] D. Lichtenberg, S. Ragimova, A. Bor et al., "Stability of mixed micellar systems made by solubilizing phosphatidylcholinecholesterol vesicles by bile salts," Hepatology, vol. 12, no. 3, 1990.

[24] K. Matsumoto, M. Imasato, Y. Yamazaki et al., "Claudin 2 deficiency reduces bile flow and increases susceptibility to cholesterol gallstone disease in mice," Gastroenterology, vol. 147, no. 5, pp. 1134-1145.e10, 2014.

[25] R. M. Schwartz, J. K. Furne, and M. D. Levitt, "Paracellular intestinal transport of six-carbon sugars is negligible in the rat," Gastroenterology, vol. 109, no. 4, pp. 1206-1213, 1995.

[26] L. S. E. Silva, A. M. de Miranda, C. L. de Brito Magalhães, R. C. Dos Santos, M. L. Pedrosa, and M. E. Silva, "Diet supplementation with beta-carotene improves the serum lipid profile in rats fed a cholesterol-enriched diet," Journal of Physiology and Biochemistry, vol. 69, no. 4, pp. 811-820, 2013. 


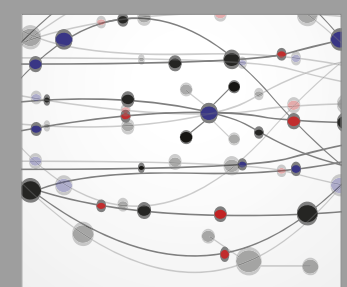

The Scientific World Journal
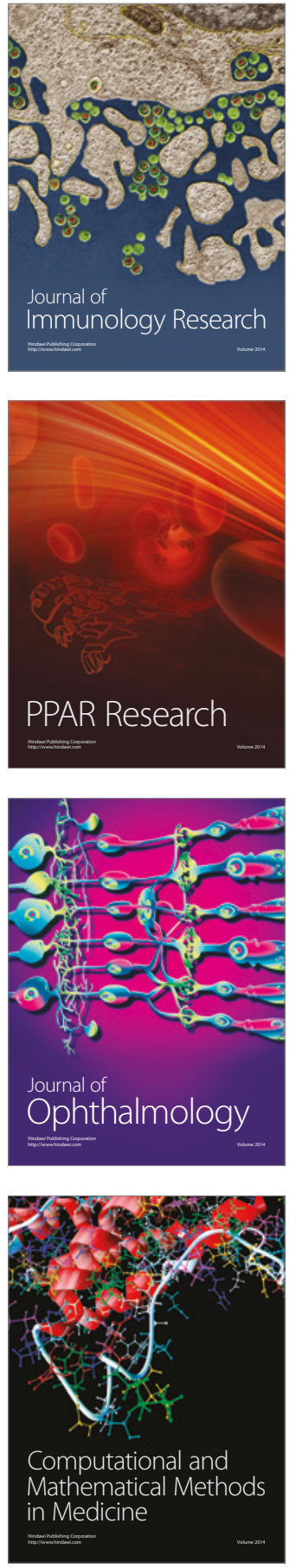

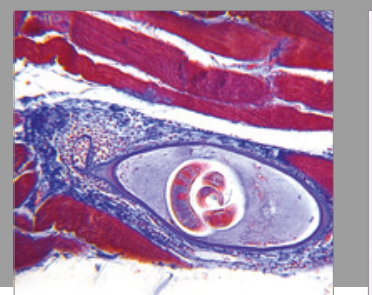

Gastroenterology Research and Practice
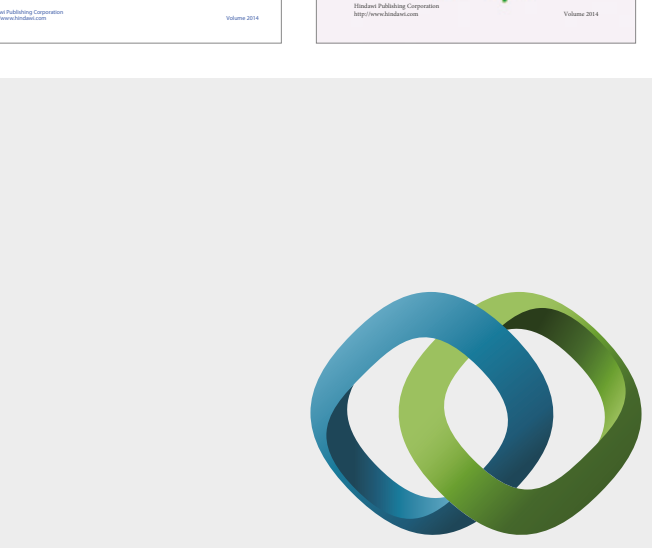

\section{Hindawi}

Submit your manuscripts at

https://www.hindawi.com
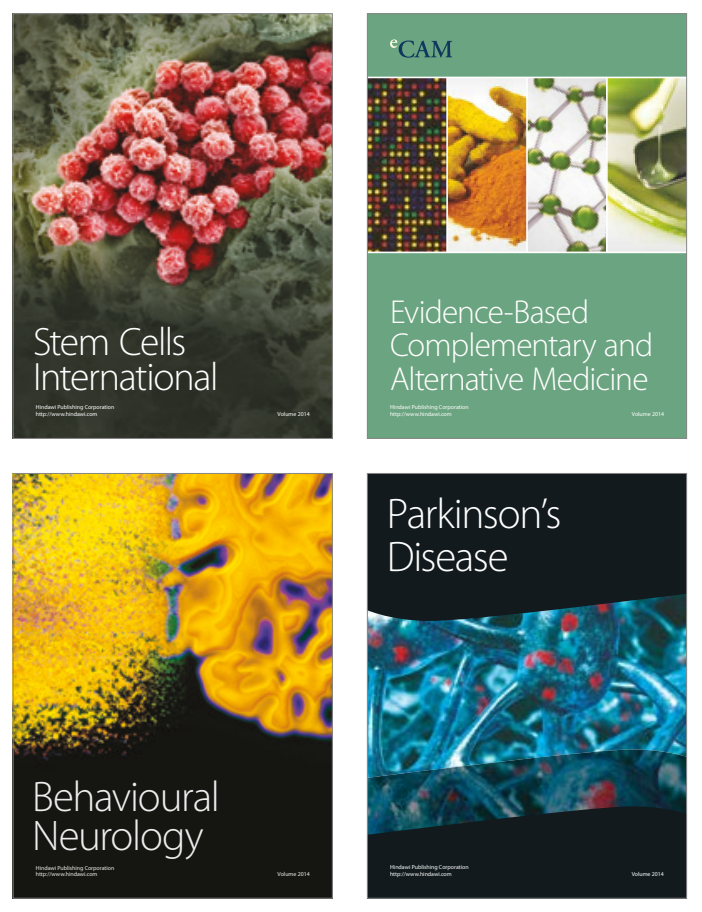
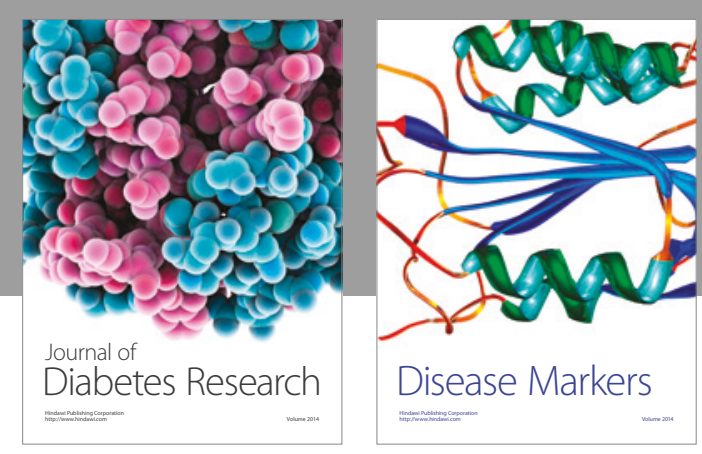

Disease Markers
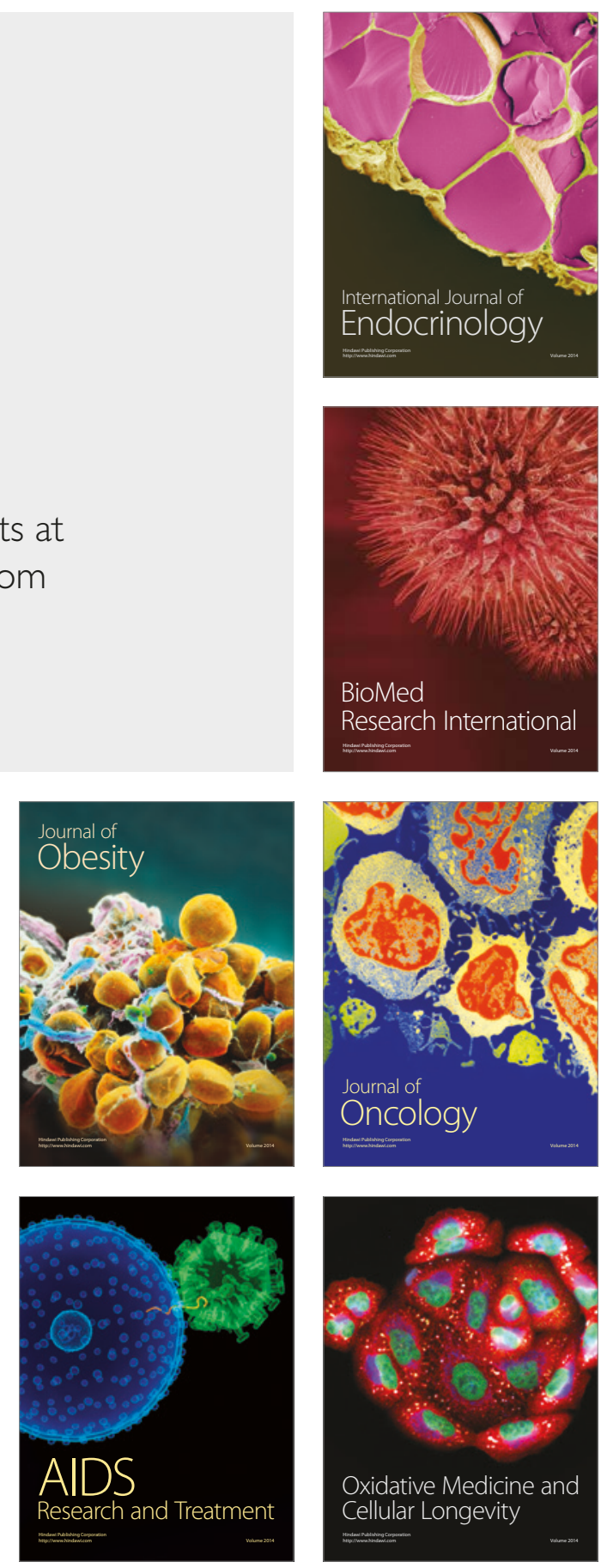